\section{Chronic kidney disease, spirituality and religiosity: a systematic overview with the list of eligible studies}

\author{
Nicola Luigi Bragazzi, \\ Giovanni Del Puente2 \\ 1Department of Health Sciences, School \\ of Public Health, University of Genoa; \\ 2Department of Neuroscience, \\ Rehabilitation, Ophthalmology, Genetics, \\ Maternal and Child Health, Section of \\ Psychiatry, University of Genoa, Italy
}

\section{Abstract}

Chronic Kidney Disease (CKD) has a tremendous psychological burden, which sometimes is overlooked or underestimated in the daily clinical routine practice, since in the health care process physicians prefer to focus on the objective aspects of the pathology. In this contribution, we make a systematic overview of the relationship between spirituality/religiosity and CKD, an emerging theme which only recently has raised interest from the scientific community despite its importance. We investigate different variables, axis and categories (from the quality of life to customer's satisfaction, treatment adherence and therapeutic alliance, clinical parameters, as well as overall survival, and coping strategies adopted by the patient). Moreover, we underpin the principal clinically relevant implications (like the possibility of psycho-therapeutic interventions based on the spiritual and religious attitudes of the patient) and we discuss the main gaps, methodological barriers and difficulties in the field, fostering and advocating further research and clinical studies. This last aspect, together with the quality assessment of the studies, will be further explored in the second part of the study.

\section{Introduction}

\section{Chronic kidney disease}

Chronic kidney disease (CKD) is an important public health problem with a tremendous burden and social-economical implications, ${ }^{1-3}$ affecting only in the USA more than 20 million people (that is to say, $10 \%$ of the overall population) and with an expected increasing prevalence in the near future. ${ }^{1}$ It is a condition in which the kidneys damage leads to a loss of their physiological functions (filtering blood, regulating the pressure, maintaining acids and bases homeostasis, regulating fluids and electrolytes). Thus, wastes are not properly removed, their level tends to increase and this leads to other complex health problems and comorbidities, including above all complications such as cardiovascular disease (CVD), ${ }^{4}$ hypertension, ${ }^{5}$ anemia, ${ }^{6}$ malnourishment (in particular, protein-energy malnutrition, or PEM), ${ }^{7}$ endocrinological disorders (impaired balance of electrolytes, erythropoietin deficiency, secondary hyperparathiroidism, hyperinsulinism, growth hormone impairment, sexual dysfunctions), 8 bone diseases (osteoporosis, osteomalacia, osteitis fibrosa, osteodistrophy, adynamic bone and other bone abnormalities that are included in the complex clinical syndrome termed as renal bone disease, or renal osteodistrophy, or CKD-mineral and bone disorder), ${ }^{9}$ infections (especially, hepatitis C), ${ }^{10}$ cancer, ${ }^{11}$ and mental disorders like dementia and cognitive impairment.12-14 People with early CKD tend not to feel any kind of symptom and the only ways to detect CKD as earlier as possible are through a blood test to estimate kidney function, and a urine test to quantitatively assess the entity of kidney damage.

For this reason, CKD is often diagnosed when patients need replacement therapy (that is to say, kidney transplantation, chronic haemodialysis or peritoneal dialysis), since CKD is usually an irreversible and progressive disease and can lead to kidney failure, also called CRF (Chronic Renal Failure), whose last stage is termed End Stage Renal Disease (ESRD), which is fatal if it is not properly treated. Once detected, CKD can be managed through medication and lifestyle changes to slow down the disease progression, and to prevent or delay the onset of kidney failure as much as possible.

CKD is more common among women than men, more than $35 \%$ of people aged 20 years or older with diabetes have CKD, more than $20 \%$ of people aged 20 years or older with hypertension have CKD. ${ }^{1-3}$ CKD is a complex and chronic disease, and patients experience a daily suffering, dependence on others and on machine and have to undergo to continuous medication. Thus many psychological variables could be involved, from anxiety and depression, ${ }^{15-19}$ as well as patient's personality, ${ }^{20}$ sexual functioning to self-esteem and to patient's beliefs and preferences, ${ }^{21,22}$ including patient-reported measures (PROM), such as HRQoL (healthrelated quality of life). ${ }^{23,24}$ These parameters are worthy being investigated and understood by the clinicians, since they could impact on patient's compliance and adherence to the therapy and to the clinical outcome. ${ }^{25-28}$ Moreover, recently, medicine has shifted from a P0 (paternalistic and not patient-centered) model to a highly participatory and interactive P6 paradigm, in which psycho-cognitive
Correspondence: Nicola Luigi Bragazzi,

Department of Health Sciences, School of Public Health, University of Genoa, via Pastore 1, 16132 Genoa, Italy.

Tel. +39.010 .3537664 - Fax: +39.010 .3537669$

E-mail: robertobragazzi@gmail.com

Key words: chronic kidney disease, religiosity, spirituality, spiritual well-being.

Conflict of interests: the authors report no conflict of interests.

Received for publication: 19 December 2012.

Revision received: 4 February 2013.

Accepted for publication: 4 February 2013.

This work is licensed under a Creative Commons Attribution NonCommercial 3.0 License (CC BYNC 3.0).

(C) Copyright N. Luigi Bragazzi and G. Del Puente. 2013

Licensee PAGEPress, Italy

Health Psychology Research 2013; 1:e26

doi:10.4082/hpr.2013.e26

aspects are considered and integrated into the bio-psycho-social framework, ${ }^{29-32}$ whose natural evolution is called the bio-psycho-socialspiritual model. We have to consider that the six Ps stay for personalized, predictive, participatory, preventive, psycho-cognitive, and public, that is to say a holistic and highly integrated framework of health-care process. Investigating the psychological aspects of CKD could have profound clinically relevant implications and could pave the way for a personalized treatment, based on the spiritual, religious and existential attitudes of the patient and fully integrated in the entire health-care process. 33 The religious beliefs and spirituality of patients on replacement therapy, peritoneal dialysis, or haemodialysis therapy, as well as waiting for a kidney transplant or living with a transplanted organ have not been studied extensively so far. Studies of the dialysis and transplantation population seem to indicate that religion may be associated with increased patient satisfaction with life and increased levels of social support, even if in some cases the results are mixed and do not reach the consistency of a scientific evidence. In this manuscript, we identify the relationships that have been studied so far, the gaps in the research field, together with the methodological difficulties and barriers, in order to foster further advancements and to help physicians.

Religious beliefs and spirituality: gaps, methodological barriers and difficulties

Scholars tend to distinguish between reli- 
giosity (as an institutionalized, structured, organized array of creed items and of sacredrelated rituals and practices) and spirituality (as an existential need for transcendence and connection with the Universe, the experience of the divine, the search for a meaning and a purpose, the sense of inner peace, spiritual strength, well-being and completeness, as well as a perception of hope, optimism and faith, according to the World Health Organization Quality Of Life-Spirituality Religion and Personal Beliefs group), even though this distinction, if clear in theory, is poorly respected in the psychological practice and literature. Indeed there is no universal scientific consensus about an operational definition of spirituality. This represents the first barrier. Moreover, some scholars maintain that there would be a publication bias about the putative relationship between spiritual attitudes and clinical outcome in chronic pain patients, since only positive results have been published and lack of spirituality is poorly investigated. Another hurdle is that, despite the North American Nursing Diagnosis AssociationInternational (NANDA-I) acknowledged the spiritual anguish response, originally spiritual distress, as a pertinent nursing diagnosis, there is apparently few interest in the spiritual category from the clinicians. ${ }^{34}$ Other biases may be due to the fact that the available religiosity and spirituality scales could fail to quantify religiosity or spirituality, capturing instead other factors directly or indirectly related to them, as suggested by Berman and co-workers. ${ }^{35}$ In fact, it is rather difficult to rigorously assess and precisely measure both religiosity and spirituality, and thus a quantitative study should be coupled with a qualitative one. A further limitation of the studies could be linked with the so-called center-effect, defined by Berman et al. as the extent to which the unit and staff reflect the dominant religious modes of their patient population. 35

\section{Method}

This umbrella systematic review was conducted searching on PubMed/MEDLINE, Scopus, SCIELO, LILACS, CINAHL, EMBASE Nursing, ISI Web of Knowledge, using a combination of strings and MeSH (Medical) where appropriate. Duplicate references were eliminated. Only peer-reviewed articles and studies written in English were selected; reviews, and editorials were not included. .5-89 $^{\text {The eligible }}$ studies are summarized in Supplementary Table 1. A brief recall to the stages of ESRD and

Table 1. A summary of end-stage renal disease stages (modified from KDOQI, clinical practice guidelines for chronic kidney disease: evaluation, classification, and stratification).

\begin{tabular}{llc} 
Stage & Comment & GFR (MI/M/in/1.73 M2) \\
1 & Kidney damage with normal or relatively high GFR & $\geq 90$ \\
2 & Mild reduction in GFR & $60-89$ \\
\hline 3 & Moderate reduction in GFR & $30-59$ \\
4 & Severe reduction in GFR & $15-29$ \\
\hline 5 & Established kidney failure & $<15$ \\
\hline
\end{tabular}

GFR, glomerular filtration rate.

the investigated categories are summarized in Tables 1 and 2.

\section{Main findings}

In this contribution, we made a systematic overview of the relationship between spirituality/religiosity and CKD, an emerging theme which only recently has raised interest from the scientific community despite its importance, investigating different axis and categories (from the quality of life to customer's satisfaction, treatment adherence and therapeutic alliance, from clinical parameters, as well as overall survival, to the coping strategies adopted by the patient).

These investigated relationships are summarized as follows.

\section{Spirituality versus religiosity}

Some authors observed a different correlation between spirituality and religiosity, for example Song and collaborators, ${ }^{36}$ Spinale et al., ${ }^{37}$ Tanyi, 38 on the contrary Valcanti and coworkers, ${ }^{39}$ found that spiritual coping could not be reduced to a non-religious form of coping, and also other authors such as Theofilou, ${ }^{40}$ ReigFerrer, ${ }^{41}$ Davison, ${ }^{42}$ Martin, ${ }^{43}$ observed a strict link between religiosity and spirituality. However, some authors, such as Rambod, ${ }^{44}$ did not make any distinction between religiosity and spirituality and used these two terms/domains as interchangeable. Moreover, some authors reported differences among the different creed and religious affiliations, while others emphasized that there is no need to tailor nephrology nursing to ethnic variables, such as the work by 0'Brien. ${ }^{45}$ While spirituality, spiritual well-being and religiosity are well-known categories, the concept of impaired spirituality and spiritual anguish are emerging ones, for example in the work by De Cássia Lopes Chaves. ${ }^{46}$

Table 2. Parameters investigated in this study.

\begin{tabular}{ll}
$\begin{array}{l}\text { Investigated parameters } \\
\text { Demographic data }\end{array}$ & Examples \\
Laboratory data & $\begin{array}{l}\text { Serum sodium, potassium, calcium, phosphorus, chloride, creatinine, uric acid, BUN, CO2 concentration, } \\
\text { systolic and diastolic pressure, hematocrit, weight and weight change }\end{array}$ \\
\hline Clinical data & $\begin{array}{l}\text { Cause of the CRF (chronic glomerulonephritis, diabetes mellitus, hypertension), ESRD stage, time since the diagnosis, } \\
\text { kind of treatment, psychopathology (suicide attempt, depression, anxiety), EEG, co-morbidities, nutritional assessment } \\
\text { (SGA, triceps skinfolds, mid upper arm circumference, mid arm muscle circumference, albumin, transferrin) }\end{array}$ \\
Clinical outcome & Survival and mortality rate, QOL \\
\hline Psychosocial parameters & $\begin{array}{l}\text { Psychosocial adjustment, illness beliefs, representation and awareness, emotional reaction to the disease, locus of } \\
\text { control, body perception and image, self-perception, personality correlates, perceived social support and social ne } \\
\text { works, stressors and stress levels, coping skills and strategies }\end{array}$ \\
Spirituality and religiosity & Religious affiliation, attendance, literature, pray, spiritual well-being \\
\hline Patient's behaviors & $\begin{array}{l}\text { Sick role behavior, compliance, adherence, and willingness to cooperate and collaborate with the medical staff, } \\
\text { treatment choice and preference }\end{array}$ \\
\hline
\end{tabular}

BUN, Blood Urea Nitrogen; CRF, Chronic Renal Failure; ESRD, End-Stage Renal Disease; QOL, Quality Of Life; SGA, Subjective Global Assessment. 
Spirituality/religiosity and demographic characteristics of the studied population

Authors such as Reig-Ferrer, ${ }^{41}$ Valcanti, ${ }^{39}$ Kao, ${ }^{47}$ Kimmel, ${ }^{48}$ Lai, ${ }^{49}$ found that spiritual beliefs were higher among women. No differences has been observed as far as ethnicity is concerned, for example in the survey conducted by Welch and collaborators, 50 but some scholars instead found some differences, such as Weisbord et al. ${ }^{51}$

\section{Spirituality/religiosity and quality of life}

Many studies show that religious and spiritual beliefs are associated with decreased perception of burden of illness, decreased level of depression, increased perception or use of social support, and higher perception of quality of life in a CKD/ESRD population, such as in the work by Wechpradit, 52 Lucchetti, 55 Patel, 56 even if some authors reported only partial or weaker correlations, like in the studies by Davison.42,53 Quality of life and spirituality score are negatively correlated, since as the physical condition of the patient deteriorates the spiritual need increases and becomes stronger. However other studies, such as the research carried out by Kao and co-workers, ${ }^{47}$ have found mixed results, since both patients with no spiritual/religious beliefs and those with strong attitudes have reported high scores using SF-36.

\section{Spirituality/religiosity and cus- tomer satisfaction}

Some studies have found that religious beliefs are related strongly to measures of satisfaction with life, whereas religious behaviors are related to satisfaction with medical care. Berman and co-workers have found that higher spiritual scores on a 74 HD population correlated with higher customer satisfaction and perception of quality of the medical care. 35

\section{Spirituality/religiosity and treat- ment adherence}

Spirituality/religiosity and treatment adherence, which is defined as the extent to which an individual chooses behavior that coincides with a clinical prescription. Scholars found a positive relationship, such as Weil, 57 Tany. ${ }^{61}$ However, Berman and co-workers did not find a correlation. 35 Other studies present mixed or negative results, such as the work by Kranenburg and co-workers. ${ }^{58}$

\section{Spirituality/religiosity and treat- ment choice and preference}

Spirituality/religiosity and treatment choice and preference (end-of-life care versus dialysis withdrawal), like in the study carried out by Davison. ${ }^{59,60}$

\section{Spirituality/religiosity and thera- peutic alliance}

Patient are supposed to be more collaborative with the physicians and to be more involved or feeling like to being involved in the health-care process.

\section{Spirituality/religiosity and clinical parameters}

Despite some studies have found no relationship between spirituality and clinical factors, other scholars have reported a profound impact of spiritual attitudes on sleep disturbs, which are very frequent in dialysis patients, ${ }^{62,63}$ such as the research by Young and co-workers, ${ }^{64,65}$ the outcome of the palliative care, ${ }^{66,67}$ the nutritional status, ${ }^{68}$ but for example intriguingly no relationship was found between spirituality scores and co-morbidity (as assessed using the Charlson co-morbidity index), as emerging in the work by Finkelstein and co-workers. ${ }^{69}$ However, a correlation between spirituality/religiosity and symptom severity was found by Schwartz and co-workers. ${ }^{70}$

\section{Spirituality/religiosity and mental health}

There is a good consensus about the positive impact of spiritual well-being and depression and anxiety, such as in the work by Theofilou, ${ }^{40}$ Lucchetti, 55 even though Ko and collaborators failed to find any correlation. ${ }^{71}$

\section{Spirituality/religiosity and locus of control}

There are very few studies focusing on this topic, some interesting exceptions are given by the study carried out by Theofilou, ${ }^{40}$ Ibrahim and co-workers, ${ }^{54}$ Davison et al. ${ }^{50-60}$

\section{Spirituality/religiosity and survival}

This is a topic that has raised interest only recently and very few studies exist about this relationship, because of different difficulties and methodological barriers. Foster and collaborators were the first to investigate the relationship between a religious affiliation and survival rate. ${ }^{72}$ Greenberg et al. ${ }^{73}$ confirmed this result. Spinale and co-workers, 37 for example, have been able to prove a positive correlation between spiritual beliefs and involvement and survival, in a sample of 166 ESRD patients, finding that religion is used more as a psycho-social support than as a coping strategy. However, the impact on survival remains only partially explained, since after applying adjustment not only the scores and data have confirmed the correlation, and thus further studies are needed in order to replicate these findings and to shed light on this relationship.

\section{Spirituality/religiosity and coping strategies}

In general, there is a consensus that spirituality and religion can be used as a coping strategies in order to overcome the psychological burden of CKD. There seems to be two principal coping strategies categories: the first dimension is using religion in order to enhance the psychological adjustment and to experience greater existential well-being (EWB), such as in the work by Elliott, ${ }^{74}$ Breckenridge, ${ }^{75}$ Baldree, ${ }^{76}$ Walton, ${ }^{77}$ Tanyi, ${ }^{78,79}$ Caress, ${ }^{80}$ the second one is the social support mediated by religion itself, like in the work by Spinale, ${ }^{37}$ Shah. 81 The last strategy apparently is less used.

\section{Spirituality/religiosity and psycho- therapeutic interventions}

On the basis of the possible relationship between spirituality and better clinical outcome in CKD populations, some scholars have put forward the proposal of introducing meditation or spiritual counseling as complementary supporting therapy. ${ }^{82-86}$ Spiritual counseling, in fact, is expected to make the patient search for a meaning or a purpose of his/her disease and the presence of a chaplain or a religious figure could make the patient more self-aware of his/her own spiritual resources and subsequently better cope with the disease. However, once again, too few studies exist and a randomized clinical trial would be needed. Some scholars, such as Davison, speculate that the advent of new and modern medical technologies and devices could have lead to an underestimation of spiritual and pastoral needs and thus to an under-treatment. The author advocates that religious/spiritual services and resources should be made more available in the hospitals, integrated into a holistic nursing and health-care process. Another interesting point is whether or not this psychological intervention should be tailored to the kind of treatment (hemodialysis versus peritoneal dialysis), but few authors found differences between the two treatments, such as Parker and collaborators. 87 Psycho-spiritual interventions should be applied at the light of the evidence-based spirituality, avoiding those practices which did not reach an adequate level of evidence, such as the intercessory prayer, as emerging in the beautiful demonstration by Matthews et al. 88

The biological and cellular basis of these relationships are still unclear, but a major role may be played by regulation of stressors and immunological/inflammatory axis (release of cytokines and interleukines, resistance to infection). 89

As a further remark we should notice that most of these studies are cross-sectional and not longitudinal, so a causal inference cannot 
be extrapolated. They are not randomized, apart from few exceptions, and the sample is often selected as convenience sample, thus the results cannot be generalized to the general population.

\section{Conclusions}

Patient's spiritual attitudes, coping strategies, preferences and health-related beliefs and behaviors, as well as end-of-life care needs, are poorly routinely reported by the nephrology staff and are not currently systematically integrated into their renal care, such as pain and symptom management, advance care planning, and psychosocial and spiritual support even thought some surveys have shown that CKD have diffuse spiritual needs. An integrated, holistic, approach in the framework of $\mathrm{P} 6$ medicine is thus advocated as necessary to provide the patient with his/her demands and needs and to deliver a true patient-centered treatment. Only recently spiritual beliefs are being investigated by scholars, a theoretical foundation is still lacking and further studies are need to establish a scientifically sound impact on health-care.

\section{References}

1. Centers for Disease Control and Prevention. National chronic kidney disease fact sheet: general information and national estimates on chronic kidney disease in the United States, 2010. Atlanta, GA: US Department of Health and Human Services, Centers for Disease Control and Prevention; 2010.

2. Plantinga LC. Socio-economic impact in CKD. Nephrol Ther. 2013 Jan 11. [Epub ahead of print]

3. Couser WG, Remuzzi G, Mendis S, Tonelli M. The contribution of chronic kidney disease to the global burden of major noncommunicable diseases. Kidney Int 2011; 80:1258-70.

4. Herzog CA, Asinger RW, Berger AK, et al. Cardiovascular disease in chronic kidney disease. A clinical update from kidney disease: improving global outcomes (KDIGO). Kidney Int 2011;80:572-86.

5. Peixoto AJ, Orias M, Desir GV. Does kidney disease cause hypertension? Curr Hypertens Rep 2013 Jan 24. [Epub ahead of print]

6. Dmitrieva 0, de Lusignan S, Macdougall IC, et al. Association of anaemia in primary care patients with chronic kidney disease: cross sectional study of quality improvement in chronic kidney disease
(QICKD) trial data. BMC Nephrol 2013; 14:24.

7. Kuhlmann MK, Kribben A, Wittwer M, Horl WH. OPTA - malnutrition in chronic renal failure. Nephrol Dial Transplant 2007;22:13-9.

8. Leavey SF, Weitzel WF. Endocrine abnormalities in chronic renal failure. Endocrinol Metab Clin North Am 2002;31: 107-19.

9. Martin KJ, González EA. Metabolic bone disease in chronic kidney disease. J Am Soc Nephrol 2007;18:875-85.

10. Al-Freah MA, Zeino Z, Heneghan MA. Management of hepatitis $\mathrm{C}$ in patients with chronic kidney disease. Curr Gastroenterol Rep 2012;14:78-86.

11. Hartmann A, Jenssen T, Holdaas $H$. Diabetes, chronic kidney disease and cancer risk. Nephrol Dial Transplant 2012;27: 3018-20.

12. Sasaki Y, Marioni R, Kasai M, et al. Chronic kidney disease: a risk factor for dementia onset: a population-based study. The Osaki-Tajiri Project. J Am Geriatr Soc 2011;59:1175-81.

13. Yaffe K, Ackerson L, Hoang TD, et al. Retinopathy and cognitive impairment in adults with CKD. Am J Kidney Dis 2013;61:219-27.

14. Nasser Mel T, Shawki S, El Shahawy Y, Sany D. Assessment of cognitive dysfunction in kidney disease. Saudi J Kidney Dis Transpl 2012;23:1208-14.

15. Theofilou P. Depression and anxiety in patients with chronic renal failure: the effect of sociodemographic characteristics. Int J Nephrol 2011;2011:1-6.

16. Karamanidou C, Theofilou P, GinieriCoccossis M, et al. Anxiety, depression and health beliefs in end-stage renal disease (ESRD) patients. Poster presentation. 17th European Congress of Psychiatry, European Psychiatric Association. European Psychiatry 2009;24 Suppl 1:651.

17. Theofilou P. Anxiety and depression: a comparison among hemodialysis and kidney transplantation patients. J Depression Anxiety 2011:1:1-2.

18. Vasilios K, Vasilios K. Depression in patients with CKD: a person centered approach. J Psychol Psychother 2012; S3:002.

19. Feng L, Bee Yap K, et al. Depressive symptoms in older adults with chronic kidney disease: mortality, quality of life outcomes, and correlates. Am J Geriatr Psychiatry 2012 Aug 14. [Epub ahead of print]

20. Muehrer RJ, Becker BN. Psychosocial factors in patients with chronic kidney disease: life after transplantation: new transitions in quality of life and psychological distress. Sem Dial 2005;18:124-31.

21. Theofilou P. Sexual functioning in chronic kidney disease: the association with depression and anxiety. Hemodial Int 2012;16:76-81.

22. Theofilou P. Self-esteem in Greek dialysis patients: the contribution of health locus of control. Iran J Kidney Dis 2012;6:136-40.

23. Gokal R. Quality of life in patients undergoing renal replacement therapy. Kidney Int 1993;40:S23-7.

24. Merkus MP, Jager KJ, Dekker FW, et al. Quality of life in patients on chronic dialysis: self-assessment 3 months after the start of treatment. The Necosad Study Group. Am J Kidney Dis 1997;29:584-92.

25. Theofilou P. The effect of sociodemographic features and beliefs about medicines on adherence to chronic kidney disease treatment. J Clin Res Bioethics 2012; $3: 1-5$.

26. Theofilou P. Identifying risk factors associated with compliance to medication in elderly kidney transplant patients. J Transplant Technologies Res 2012;2:1-2.

27. Theofilou P. Factors affecting level of compliance in chronic patients. Internal Med 2012;2:e106.

28. Theofilou P. Interventions to support medication adherence in individuals with chronic disease: the role of health professionals. J Community Med Health Edu 2012; 2:e104.

29. Bragazzi NL. From P0 to P6 medicine, a model of highly participatory, narrative, interactive, and augmented medicine: some considerations on Salvatore Iaconesi's clinical story. Patient Prefer Adherence 2012. [In press].

30. Bragazzi NL, Del Puente G. The bio-psycho-social model and beyond: its limitations and the need for a new model. A response to Eid's editorial the bio-psychosocial model: how accurate and valid is it? Open Access Scientific Reports 2012. [In press].

31. Bragazzi NL. Children, adolescents, and young adults participatory medicine: involving them in the health care process as a strategy for facing infertility issue. Am J Bioethics 2013;13;43-4.

32. Bragazzi NL, Del Puente G. Why P6 medicine needs clinical psychology and a transcultural approach. Health Psychology Research 2013;1:e5.

33. Blumenfield M. Consultation-liaison psychiatry. Philadelphia: Lippincott Williams and Wilkins; 2003.

34. Twibell RS, Wieseke AW, Marine M, Schoger J. Spiritual and coping needs of critically ill patients: validation of nursing diagnoses. Dimens Crit Care Nurs 1996; 15:245-53.

35. Berman E, Merz JF, Rudnick M, et al. Religiosity in a hemodialysis population and its relationship to satisfaction with 
medical care, satisfaction with life, and adherence. Am J Kidney Dis 2004;44:48897.

36. Song MK, Hanson LC. Relationships between psychosocial-spiritual well-being and end-of-life preferences and values in African American dialysis patients. J Pain Symptom Manage 2009;38:372-80.

37. Spinale J, Cohen SD, Khetpal P, et al. Spirituality, social support, and survival in hemodialysis patients. Clin J Am Soc Nephrol 2008;3:1620-7.

38. Tanyi RA, Werner JS. Adjustment, spirituality, and health in women on hemodialysis. Clin Nurs Res 2003;12:229-45.

39. Valcanti CC, Chaves Ede C, Mesquita AC, et al. Religious/spiritual coping in people with chronic kidney disease undergoing hemodialysis. Rev Esc Enferm USP 2012;46:838-45.

40. Theofilou P. The relationship between religion/spirituality and mental health in patients on maintenance dialysis. $\mathrm{J}$ Women's Health Care 2012;S2:001.

41. Reig-Ferrer A, Arenas MD, Ferrer-Cascales $\mathrm{R}$, et al. Evaluation of spiritual well-being in haemodialysis patients. Nefrologia 2012;32:731-42.

42. Davison SN, Jhangri GS. Existential and religious dimensions of spirituality and their relationship with health-related quality of life in chronic kidney disease. Clin J Am Soc Nephrol 2010;5:1969-76.

43. Martin JC, Sachse DS. Spirituality characteristics of women following renal transplantation. Nephrol Nurs J 2002;29:57781.

44. Rambod M, Rafii F. Perceived social support and quality of life in Iranian hemodialysis patients. J Nursing Scholarship 2010;42: 242-9.

45. 0'Brien ME. Religious faith and adjustment to long-term hemodialysis. J Relig Health 1982;21:e80.

46. De Cássia Lopes Chaves E, De Carvalho EC, De Souza Terra F, De Souza L. Clinical validation of impaired spirituality in patients with chronic renal disease. Rev Lat Am Enfermagem 2010;18:309-16.

47. Kao TW, Chen PC, Hsieh CJ, et al. Correlations between spiritual beliefs and health-related quality of life of chronic hemodialysis patients in Taiwan. Artif Organs 2009;33:576-9.

48. Kimmel PL, Emont SL, Newmann JM, et al. ESRD patient quality of life: symptoms, spiritual beliefs, psychosocial factors, and ethnicity. Am J Kidney Dis 2003;42:713-21.

49. Lai CF, Kao TW, Wu MS, et al. Impact of near-death experiences on dialysis patients: a multicenter collaborative study. Am J Kidney Dis 2007;50:124-32.

50. Welch JL, Austin JK. Quality of life in black hemodialysis patients. Adv Ren Replace
Ther 1999;6:351-7.

51. Weisbord SD, Fried LF, Unruh ML, et al. Associations of race with depression and symptoms in patients on maintenance haemodialysis. Nephrol Dial Transplant 2007;22:203-8.

52. Wechpradit A, Thaiyuenwong J, Kanjanabuch T. Health promotion behaviors and related factors in end stage renal disease patients treated with continuous ambulatory peritoneal dialysis. J Med Assoc Thai 2011;94 Suppl 4:S113-8.

53. Davison SN, Jhangri GS. The relationship between spirituality, psychosocial adjustment to illness, and health-related quality of life in patients with advanced chronic kidney disease. J Pain Symptom Manage 2012 Aug 20. [Epub ahead of print].

54. Ibrahim N, Desa A, Chiew-Tong NK. Religious coping as mediator between illness perception and health-related quality of life among chronic kidney disease patients. Asian Social Sci 2012;8:23-31.

55. Lucchetti G, de Almeida LG, Lucchetti AL. Religiousness, mental health, and quality of life in Brazilian dialysis patients. Hemodial Int 2012;16:89-94.

56. Patel SS, Shah VS, Peterson RA, Kimmel PL. Psychosocial variables, quality of life, and religious beliefs in ESRD patients treated with hemodialysis. Am J Kidney Dis 2002;40:e1022.

57. Weil C. Exploring hope in patients with end stage renal disease on chronic hemodialysis. Nephrol Nurs J 2000;27:219-23.

58. Kranenburg LW, Kerssens C, Ijzermans JN, et al. Reluctant acceptance of xenotransplantation in kidney patients on the waiting list for transplantation. Soc Sci Med 2005;61:1828-34.

59. Davison SN. End-of-life care preferences and needs: perceptions of patients with chronic kidney disease. Clin J Am Soc Nephrol 2010;5:195-204

60. Davison SN. Facilitating advance care planning for patients with end-stage renal disease: the patient perspective. Clin J Am Soc Nephrol 2006;1:1023-8.

61. Tanyi RA, Werner JS. Women's experience of spirituality within end-stage renal disease and hemodialysis. Clin Nurs Res 2008;17:32-49.

62. Parker KP. Sleep disturbances in dialysis patients. Sleep Med Rev 2003;7:131-43.

63. Stepanski E, Faber M, Zorick F, et al. Sleep disorders in patients on continuous ambulatory peritoneal dialysis. J Am Soc Nephrol 1995; 6:192-7.

64. Yang JY, Huang JW, Kao TW, et al. Impact of spiritual and religious activity on quality of sleep in hemodialysis patients. Blood Purif 2008;26:221-5.

65. Yang JY, Huang JW, Peng YS, et al. Quality of sleep and psychosocial factors for patients undergoing peritoneal dialysis. Perit Dial Int 2007;27:675-80.

66. Kimmel PL. Psychosocial factors in adult end-stage renal disease patients treated with hemodialysis, correlates and outcomes. Am J Kidney Dis 2000;35:171-84.

67. Kimmel PL. Psychosocial factors in dialysis patients. Kidney Int 2001;59:1599-13.

68. Laws RA, Tapsell LC, Kelly J. Nutritional status and its relationship to quality of life in a sample of chronic hemodialysis patients. J Ren Nutr 2000;10:139-47.

69. Finkelstein FO, West W, Gobin J, et al. Spirituality, quality of life and the dialysis patient. Nephrol Dial Transplant 2007;22: 2432-4.

70. Schwartz CE, Merriman MP, Reed G, Byock I. Evaluation of the Missoula-vitas quality of life index - revised: research tool or clinical tool? J Palliat Med 2005;8:121-35.

71. Ko B, Khurana A, Spencer J, et al. Religious beliefs and quality of life in an American inner-city haemodialysis population. Nephrol Dial Transplant 2007;22: 2985-90.

72. Foster FG, Cohn GL, McKegney FP. Psychobiologic factors and individual survival on chronic renal hemodialysis. A two year follow-up. I. Psychosom Med 1973;35: 64-82.

73. Greenberg IM, Weltz S, Spitz C, Bizzozero OJ Jr. Factors of adjustment in chronic hemodialysis patients. Psychosomatics 1975;16:178-84.

74. Elliott BA, Gessert CE, Larson P, Russ TE. Religious beliefs and practices in endstage renal disease: implications for clinicians. J Pain Symptom Manage 2012; 44:400-9.

75. Breckenridge DM. Decisions regarding dialysis treatment modality: a holistic perspective. Holist Nurs Pract 1997;12:54-61.

76. Baldree KS, Murphy SP, Powers MJ. Stress identification and coping patterns in patients on hemodialysis. Nurs Res 1982;31:107-12.

77. Walton J. Finding a balance: a grounded theory study of spirituality in hemodialysis patients. Nephrol Nurs J 2002;29:447-56.

78. Tanyi RA, Werner JS, Recine AC, Sperstad RA. Perceptions of incorporating spirituality into their care: a phenomenological study of female patients on hemodialysis. Nephrol Nurs J 2006;33:532-8.

79. Tanyi RA, Werner JS. Adjustment, spirituality, and health in women on hemodialysis. Clin Nurs Res 2003;12:229-45.

80. Caress AL, Luker KA, Owens RG.A descriptive study of meaning of illness in chronic renal disease. J Adv Nurs 2001;33:716-27.

81. Shah VS, Ananth A, Sohal GK, et al. Quality of life and psychosocial factors in renal transplant recipients. Transplant Proc 2006;38:1283-5. 
82. Straveler R. Meditation in the dialysis clinic. Nephrol News Issues 2006;20:34.

83. Goyal M, Haythornthwaite J, Levine D, et al. Intensive meditation for refractory pain and symptoms. J Altern Complement Med 2010;16:627-31.

84. Davison SN. Chronic kidney disease: psychosocial impact of chronic pain. Geriatrics 2007;62:17-23.

85. Carosella J. Incorporating spirituality into the delivery of dialysis care: one team's perspective. Adv Ren Replace Ther 2002;9: 149-51.

86. Davison SN, Jhangri GS. Existential and supportive care needs among patients with chronic kidney disease. J Pain Symptom Manage 2010;40:838-43.

87. Parker KP, Kutner NG, Bliwise DL, et al. Nocturnal sleep, daytime sleepiness, and quality of life in stable patients on hemodialysis. Health Qual Life Outcomes 2003;1:68.
88. Matthews WJ, Conti JM, Sireci SG. The effects of intercessory prayer, positive visualization, and the expectancy on the well being of kidney dialysis patients. Altern Ther Health Med 2001;7:42-52.

89. Koenig HG, Cohen HJ, George LK, et al. Attendance at religious services, interleukin-6, and other biological indicators of immune function in older adults. Int $\mathrm{J}$ Psychiatry Med 1997;27:233-50. 